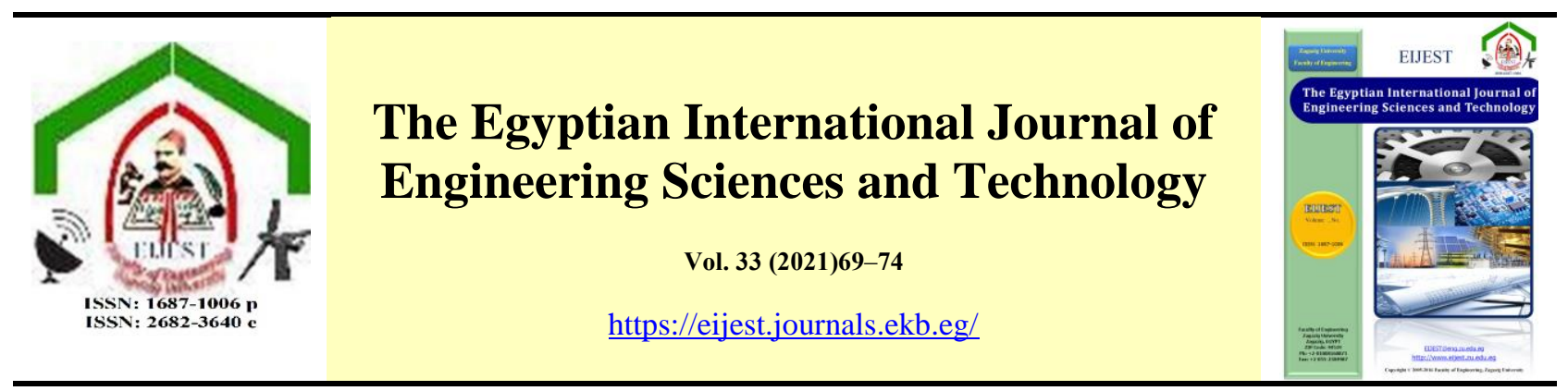

\title{
Improving Power Flow Using Static Synchronous Compensator
}

\author{
Muhammad Asad*
}

\begin{tabular}{|c|c|}
\hline \multicolumn{2}{|r|}{ Electrical Engineering, University of Gujrat, Gujrat, 50700 , Punjab, Pakistan } \\
\hline A R T I C L E I N F O & A B S T RACT \\
\hline $\begin{array}{l}\text { FACTS } \\
\text { SSSC } \\
\text { VSC } \\
\text { NPC } \\
\text { THD } \\
\text { GTO }\end{array}$ & $\begin{array}{l}\text { Due to adaptation of new lifestyles, energy demand in the power sector rapidly } \\
\text { increased day-by-day. To overcome this energy gap Flexible Alternating Current } \\
\text { Transmission System (FACTS) controllers are the most reliable option irrespective } \\
\text { to upgradation of power networks. Static Synchronous Series Compensator (SSSC) } \\
\text { is one of a series family, second generation FACTS controller used in power } \\
\text { networks to enhance power transfer capacity. In this paper, a new SSSC based } \\
\text { indirect controller is proposed for a 500kV grid station. In SSSC, multilevel, } \\
48 \text { pulse, Neutral Point Clamped (NPC) based Voltage Source Converter (VSC) is } \\
\text { implemented that injects a controllable compensating voltage in series with } \\
\text { transmission line. Almost } 20 \% \text { enhanced power flow can be achieved by using } \\
\text { proposed cost-effective SSSC controller. The aim of this paper is to find drawbacks } \\
\text { associated with previously designed controller and design a new controller for } \\
\text { power flow improvement. Also compare their results for power flow in 500kV grid } \\
\text { station using MATLAB/Simulink } 2017 \text { (a). }\end{array}$ \\
\hline
\end{tabular}

\section{Introduction}

With the sudden rise in human population and digitization, energy demand increased exponentially in today's world. Therefore, to fulfilled this energy gap, either we upgrade existing power networks or add new control devices which enhanced power transfer. Former method is not feasible. Because factors like political barriers, environmental effects, high cost (of new lines, installation, labour \& maintenance, supporting tower), space, market competition of minimum electricity cost and efficiency all cause hinderance in this role. FACTS devices are a possible promising solution to overcome this energy crises by using existing power system networks. SSSC is one of the series connected FACTS controller which enhanced power flow by injecting a voltage of controllable magnitude and direction in series. Prior to SSSC, different devices like Static Var Compensator (SVC), Thyristor Controlled Series Compensator (TCSC) etc used to enhance active power transfer. But one out of many disadvantages is that these devices are line commutated (Eremia, Liu, \& Edris, 2016; Hingorani \& Gyugyi, 2000; Le, Vo, Huynh, Nguyen-Hoang, \& Vasant, 2020; Varma \& Paserba, 2017; Wang, Li, \& Shi, 2016) having capability of control not more than one parameter at a time. SSSC is a self-commutated FACTS device (Hingorani \& Gyugyi, 2000; Kolosok, Korkina, \& Tikhonov, 2020; Nilsson, 2020) whose operation is independent to system parameters: voltage (V), current (I) and frequency (f). SSSC consists of a coupling transformer, a converter and a Direct Current (DC) capacitor with or without energy source. The basic building block of SSSC is powerelectronic based converter either it is VSC or current sourced converter (CSC). VSC is better than CSC

* Corresponding author. Tel.: +92-320-4590028.

E-mail address: contactmianasad@gmail.com. 
because CSC have certain limitations: required overvoltage protection for semi-conductor devices, required capacitor filter to terminate voltage source at AC terminal, have increased conduction loss etc. (Hingorani \& Gyugyi, 2000; Kazerani \& Ye, 2002; Kolosok et al., 2020; Zhang, Rehtanz, \& Pal, 2012).

VSC needs a capacitor for its operation. But large capacitors are not economical because they are expensive. Similarly, small capacitors cause problems at steady state operation and produce ripples in $\mathrm{V}_{\mathrm{dc}}$. Therefore, multilevel converters having small rating capacitors is the most reliable option for successful operation of FACTS devices. In the world, multilevel converters are used in FACTS devices having rating up to $100 \mathrm{MVAr}$ (Arabi, Hamadanizadeh, \& Fardanesh, 2002; Zuniga-Haro \& Ramirez, 2008). In this paper a 3-level, NPC based VSC is implemented for SSSC. This 48 pulse Gate turn-off (GTO) thyristor based VSC produced nearly sinusoidal voltage having total harmonic distortion $(\mathrm{THD})<1 \%$. Several techniques used to design SSSC to facilitate the power system having problems of stability, power flow and power quality (Chirantan, Swain, Panda, \& Jena, 2018; Gyugyi, Edris, \& Eremia, 2016; Kolosok et al., 2020; Le et al., 2020; Mahmoud, 2019; Mohamed, Luo, Pujol, \& Pacheco, 2018; Xue, Zheng, \& Rahman, 2020; Yue et al., 2018).

In (Bisht, Kumar, \& Bedi, 2020) active power flow and voltage profile improved by changing reactance using SSSC. Therefore, a reference reactance is compared with injected reactance (ratio of $V_{\text {inj }}$ to $I_{\text {line }}$ ) to provide desired compensation. That's control, depends on $\mathrm{I}_{\text {line }}$ which may cause malfunction when current exceeds from certain limits or when disturbance occur. Another problem associated with this control is that $\mathrm{V}_{\mathrm{dc}}$ kept constant which makes control complex and expensive. Because in direct controls, when SSSC needs to exchange active power through DC link then $V_{d c}$ must remain constant (Hingorani \& Gyugyi, 2000). It means, when no need of power exchange was required, we should not use direct control approach to evade complexity.

Therefore, to overcome above-mentioned problems, MATLAB/Simulink based new indirect control scheme is proposed for SSSC to enhanced the active power flow in the transmission line. In this new control, controllable voltage of VSC calculated by using vector topology irrespective to reactance calculation. Advantages of this new proposed control:

- Enhanced active power flow.

- Injected voltage is independent to transmission line current that prevents system from malfunctioning.
- Less expensive.

- Less complex.

- Magnitude of injected voltage is proportional to $\mathrm{V}_{\mathrm{dc}}$. That's by increasing or decreasing $\mathrm{V}_{\mathrm{dc}}$, the magnitude of $\mathrm{V}_{\mathrm{inj}}$ increased or decreased.

In proposed control, max. of $10 \%$, nominal line to ground voltage is injected by VSC. Significant amount of enhanced active power i.e., $19.53 \%$ (125MW) will be improved by using proposed SSSC model. Similarly, $15 \mathrm{MW}$ more active power flow as compare to previously designed model (Bisht et al., 2020). Therefore, proposed control is more efficient and cost effective i.e., using existing infrastructure or eliminate cost (of new transmission line, installation, labour \& maintenance, supporting tower and space). MATLAB/Simulink results proved the validity of this proposed model.

This paper presents step by step: Brief explanation of SSSC and its working in section 2. 48pulse, multilevel VSC design and working presents in section 3. In section 4, detailed proposed control will be explained. Similarly, section 5 presents the detail parameters of $500 \mathrm{kV}$ grid station and SSSC. Section 6 shows result and discussion. Conclusion will be discussed in section 7 .

\section{SSSC and its operation}

SSSC is one of the family member of series FACTS controller. It is used in series with transmission line to provide series compensation. The basic schematic of SSSC is shown in Fig. 1. With the help of coupling transformer, SSSC injects a nearly sinusoidal voltage of controllable and variable magnitude and/or phase angle, in series with the transmission line current. Unlike the series capacitive compensation, the series injected voltage of SSSC is independent to the transmission line current (Hingorani \& Gyugyi, 2000). But it is in quadrature with the transmission line current. Due to this quadrative relation, SSSC can simultaneously behave as a capacitive compensator or inductive compensator. If the series injected voltage, $\mathrm{V}_{\text {inj }}$ lag the transmission line current by $90^{\circ}$ then SSSC provide capacitive compensation. If the $\mathrm{V}_{\text {inj }}$ lead the transmission line current by $90^{\circ}$ then SSSC provide inductive compensation. 


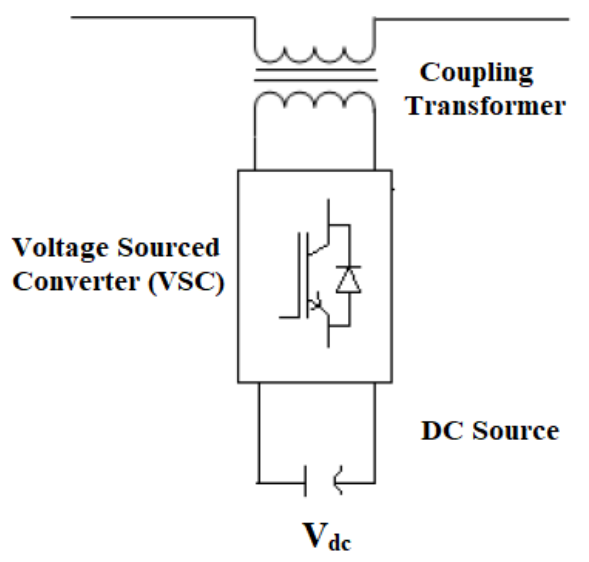

Fig. 1. Basic schematic of SSSC

\section{Voltage source converter}

Self-Commutating VSC is the basic building block of SSSC. It generates a controllable sinusoidal AC waveform against pulses generated by appropriate control system of SSSC. 3-level 48-pulse, NPC based VSC is shown in Fig. 2. It shows that VSC consist of four zigzag phase shifting transformers $\left(T_{z z, 1}-T_{z z, 4}\right)$. All of these blocks $\left(T_{z z, 1}-T_{z z, 4}\right)$ using three singlephase, 3-winding transformers to implement a 3phase, phase shifting transformer, individually. Out of these 3 windings, $\left(\mathrm{W}_{1}-\mathrm{W}_{3}\right), \mathrm{W}_{1}$ and $\mathrm{W}_{2}$ are primary windings but $\mathrm{W}_{3}$ is secondary winding. $\mathrm{W}_{1}$ and $\mathrm{W}_{2}$ of all transformers $\left(\mathrm{T}_{\mathrm{zz}, 1}-\mathrm{T}_{\mathrm{zz}, 4}\right)$ are connected in zig-zag and in series. But $\mathrm{W}_{3}$ of $\left(\mathrm{T}_{z z, 1} \& \mathrm{~T}_{z z, 3}\right)$ and $\left(\mathrm{T}_{z z, 2} \&\right.$ $\mathrm{T}_{z z, 4}$ ) connected in delta and wye, respectively. These zig zag pattern with alternating secondaries are chosen to neutralized harmonics. A phase shift (P.S) of $-30^{\circ}$ occurred between primary and secondary windings of $T_{z z, 1} \& T_{z z, 3}$. So, triplen harmonics can be eliminated. Also, an additional P.S of $+/-15^{\circ}$ applied to neutralized/suppress harmonics up to $47^{\text {th }}$ harmonics. This P.S of $+/-15^{\circ}$ subdivided as: $+15^{\circ}$ between $T_{z z, 1} \& T_{z z, 2}$ and $-15^{\circ}$ between $T_{z z, 3} \& T_{z z, 4}$. Therefore, overall P.S. of $+7.5^{\circ},-22.5^{\circ},-7.5^{\circ}$ and $37.5^{\circ}$ produced by $\mathrm{T}_{z z, 1}, \mathrm{~T}_{\mathrm{zz}, 2}, \mathrm{~T}_{\mathrm{zz}, 3} \& \mathrm{~T}_{\mathrm{zz}, 4}$, respectively. Furthermore, to achieve high efficiency, VSC should be operated at fundamental frequency.

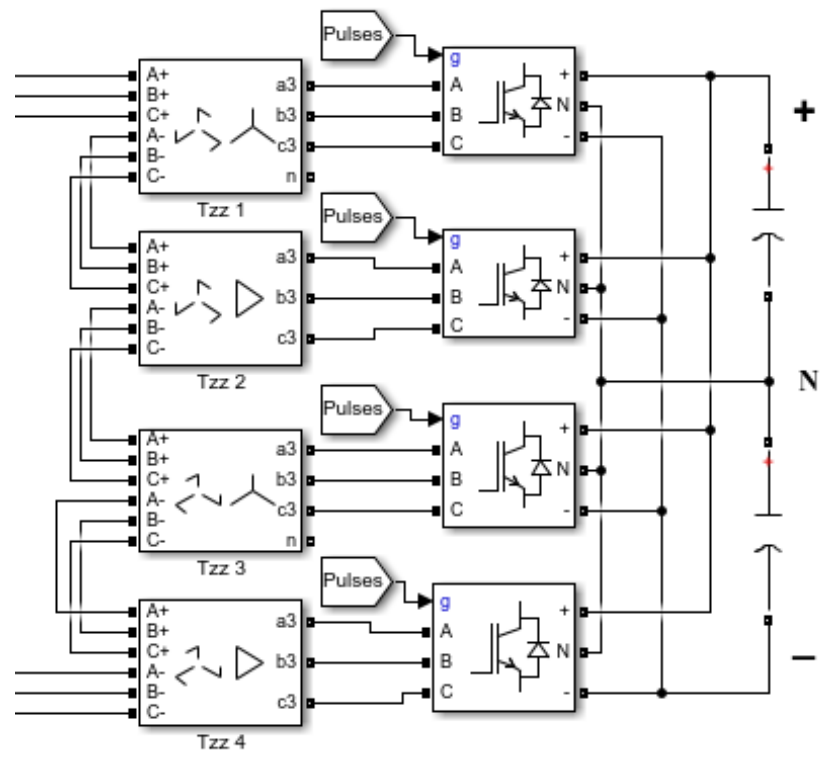

Fig. 2. Basic building block of multilevel, 48 pulse, NPC VSC

\section{Control Scheme of SSSC}

In (Bisht et al., 2020) a direct control topology of SSSC was proposed in which compensating voltage is generating by comparing reactance's as shown in Fig. 3. But, in proposed control, instead of reactance calculation, abc to dq0 transformation, shown in Fig. 5 , is used to generate controllable compensating voltage. With the help of this proposed control, the magnitude and phase angle of compensating voltage can be varied according to reference parameters to provide desired compensation. Detailed block diagram of proposed control is shown in Fig. 4.

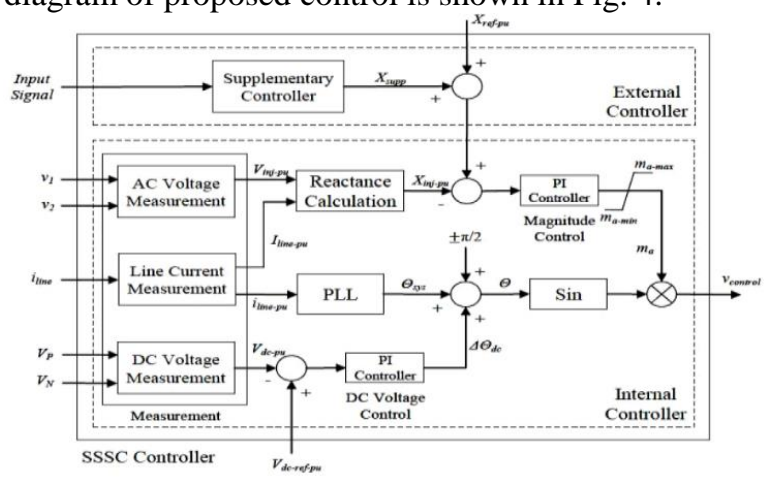

Fig. 3. Block diagram of SSSC controller (Bisht et al., 2020) 


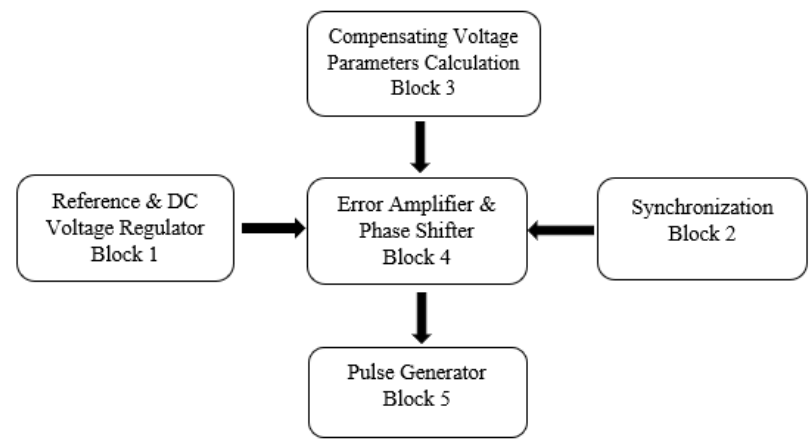

Fig. 4. Schematic of proposed SSSC controller

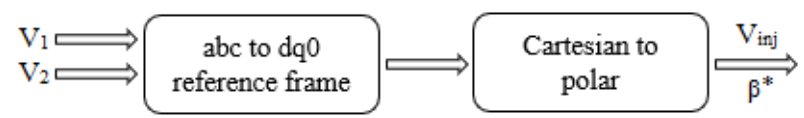

Fig. 5. Detailed control of Block 3 in Fig. 4

Block 1 ensure to kept reference values within limits and variation of DC Voltage, $\mathrm{V}_{\mathrm{dc}}$, according to reference Voltage, $\mathrm{V}_{\text {ref. }}$. Also, in this proposed control $\mathrm{V}_{\mathrm{dc}}$ varied according to nature of compensation i.e., inductive compensation and capacitive compensation. Phase locked loop (PLL) is used to synchronized the compensating voltage with the transmission line current (Block 2). Compensating Voltage magnitude and phase angle $(\beta)$ can be calculated with the help of Block 3. For this, abc to dq0 reference frame is used to convert three phase voltage into direct axis (d-axis) and quadrature axis (q-axis). D-axis voltage have zero phase difference with the transmission line current, $I_{\text {line }}$. Similarly, q-axis voltage is $90^{\circ}$ out of phase with $\mathrm{I}_{\text {line. }}$. Furthermore, output of dq0 reference frame passed through cartesian to polar transformer to generate compensating voltage magnitude and phase angle $(\beta)$. To reduced error between desired and injected compensating voltage PI controller is used to compute error. Also, Phase Shifter is used to shifts the compensating voltage $90^{\circ}$ lead or lag with respect to nature of desired compensation (Block 4). Pulse generator (Block 5) generates 48-pulse pattern according to the magnitude of and phase angle $(\beta)$ of compensating voltage. Pulses further feed to 3-level NPC VSC to perform its operation.

Proposed control scheme is evaluated on MATLAB/Simulink 2017(a).

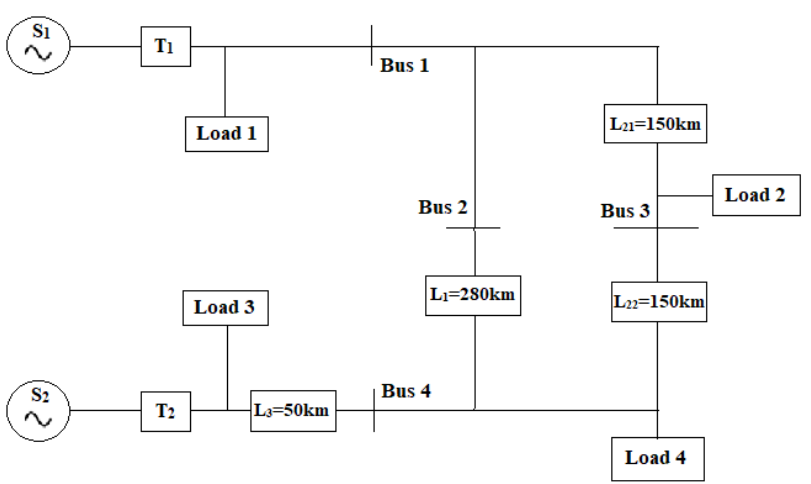

Fig. 6. Single line diagram of power system network under study.

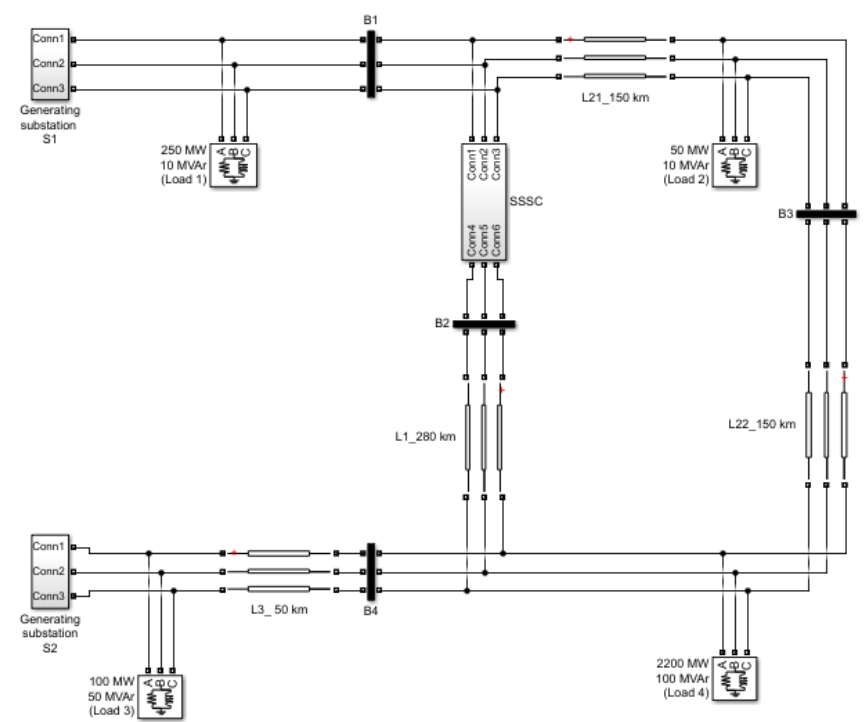

Fig. 7. MATLAB/Simulink model of power system network with compensation.

\section{Power System Network under Study}

The system has four $500 \mathrm{kV}$ buses, $\mathrm{B}_{1}, \mathrm{~B}_{2}, \mathrm{~B}_{3}$ and $\mathrm{B}_{4}$. Single line diagram of power network under study is shown in Fig. 6. Two power generating substations $S_{1}$ and $S_{2}$ of 2100MVA and 1400MVA connected with buses $\mathrm{B}_{1}$ and $\mathrm{B}_{4}$ through step-up transformer $T_{1}$ and $T_{2}$, respectively. Total capacity of $S_{1}$ and $S_{2}$ is the sum of capacities of six and four generating units, respectively. Load $\mathrm{L}_{1}$ and $\mathrm{L}_{3}$ of 250MW and $100 \mathrm{MW}$ connected with $\mathrm{B}_{1}$ and $\mathrm{B}_{4}$. Similarly, load $\mathrm{L}_{2}$ and $\mathrm{L}_{4}$ of $50 \mathrm{MW}$ and $2200 \mathrm{MW}$ connected with $\mathrm{L}_{21}$ and $\mathrm{L}_{22}$. SSSC is connected in series between $B_{1}$ and $B_{2}$ as shown in Fig. 6-7. Transmission lines, $\mathrm{L}_{1}, \mathrm{~L}_{21}, \mathrm{~L}_{22}, \mathrm{~L}_{3}$ having length $280 \mathrm{~km}, 150 \mathrm{~km}, 150 \mathrm{~km}$ and $50 \mathrm{~km}$, respectively. Transmission lines parameters (Bisht et al., 2020) are: $\mathrm{R}=0.162$ p.u. , $\mathrm{L}=0.9337$ p.u. SSSC parameters 
includes: Maximum injected voltage $=0.10$ p.u. Rating $=100 \mathrm{MVA}$, Base $\mathrm{V}=500 \mathrm{kV}$, Frequency $=$ $60 \mathrm{~Hz}, \mathrm{R}=(0.16 / 30)$ p.u , $\mathrm{L}=0.16 \mathrm{p} . \mathrm{u}, \mathrm{DC}$ link $\mathrm{V}=$ $40 \mathrm{kV}$, DC link capacitance (equivalence) $=375^{*} 10^{-6}$ $F$, Nominal power of each zig-zag transformer $=$ $(100 \mathrm{MW} / 4=25 \mathrm{MW})$.

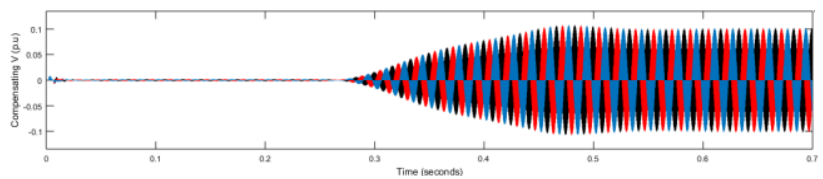

Fig. 8. Compensating voltage of SSSC at $10 \%$ injection.

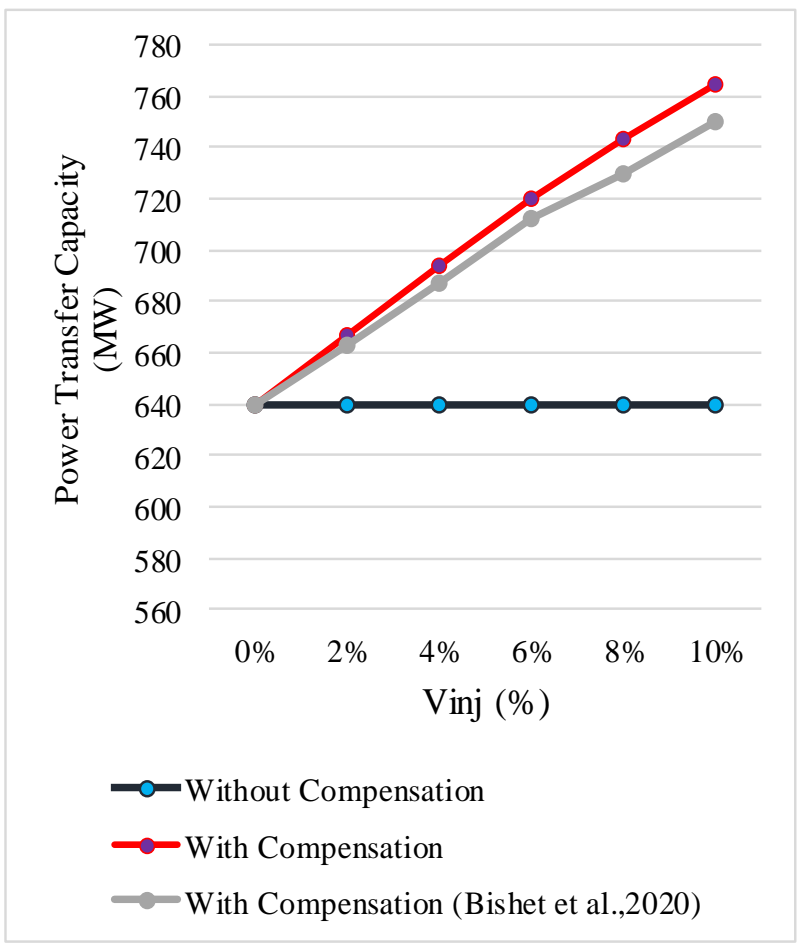

Fig. 9. Power transfer capacity at various injections with and without compensation.

\section{Results and Discussion}

SSSC is a member of series family of FACTS devices connected between buses $B_{1}$ and $B_{2}$. Here, SSSC can inject a maximum of $10 \%$ compensating voltage to improved active power flow in the transmission line $\mathrm{L}_{1}$. As shown in Fig. 8, the $\mathrm{V}_{\text {inj }}$ is zero, when SSSC is not in operation. SSSC required $0.2 \mathrm{sec}$ to fully inject compensating voltage of 0.1 p.u. when it is in operation. It is noted that magnitude of compensating voltage is directly proportional to DC link voltage. After compensation (0.1 p.u.), active power flow in $\mathrm{L}_{1}$ becomes $765 \mathrm{MW}$. That's an increase of $19.53 \%$. Similarly, improvement in active power flow at different compensating voltages (2\% to 10\%) are shown in Fig. 9 (Red Line). In (Bisht et al., 2020 ) improvement in active power flow was $17.18 \%$ at 0.1 p.u. Similarly, variation in improvement of $\mathrm{P}$ at $2 \%$ to $10 \%$ shown in Fig. 9 (Green Line). It clearly shows that proposed model improved 15MW more active power than previous control (Bisht et al., 2020). Reason behind this improvement is the reduction of inductive losses and increased in current flow due to virtual capacitance of SSSC.

\section{Conclusion}

In this paper a new control of SSSC is designed for $500 \mathrm{kV}$ grid station using 48 pulse, 3 -level NPC based VSC. Problem related to steady state power transfer is investigated using SSSC. SSSC connected between buses $B_{1}$ and $B_{2}$ that enhanced $125 \mathrm{MW}$ active power transfer through $\mathrm{L}_{1}$. A detailed comparison with or without SSSC will show the significance of this model for $500 \mathrm{kV}$ grid station. Furthermore, malfunctioning deterrence, drop in line losses, costeffectiveness and complexity reduction are major goals achieved by this model. MATLAB/Simulink 2017(a) results validate this new proposed controller of SSSC for $500 \mathrm{kV}$ grid station.

\section{References}

[1] S.Arabi, H. Hamadanizadeh \&B. Fardanesh (2002). Convertible static compensator performance studies on the NY state transmission system. IEEE Transactions on Power Systems, 17(3), 701-706. https://doi.org/10.1109/TPWRS.2002.800916

[2] K. Bisht, D. Kumar \& K. S. Bedi (2020). Enhancement of Power Transfer Capacity and Transmission Efficiency using SSSC. International Journal of Engineering and Advanced Technology, 9(3), 28462850. https://doi.org/10.35940/ijeat.c5999.029320

[3] S. Chirantan,S.C. Swain, P.Panda \& R. Jena (2018). Enhancement of power profiles by various FACTS devices in power system. Proceedings of the 2nd International Conference on Communication and Electronics Systems, ICCES 2017, 2018Janua(Icces),896-901. https://doi.org/10.1109/CESYS.2017.8321212

[4] M. Eremia,C. Liu \& A. Edris (2016). Advanced Solutions in Power Systems: HVDC, FACTS, and Artificial Intelligence (M. Eremia, C. Liu, \& A. Edris, eds.). https://doi.org/10.1002/9781119175391

[5] L. Gyugyi,A. Edris \& M. Eremia (2016). Static Synchronous Series Compensator (SSSC). In Advanced Solutions in Power Systems: HVDC, FACTS, and Artificial Intelligence (pp. 527-557). https://doi.org/10.1002/9781119175391.ch9

[6] N. G. Hingorani, \& L. Gyugyi (2000). Understanding FACTS. https://doi.org/10.1002/9780470546802 
[7] M. Kazerani \& Y. Ye (2002). Comparative evaluation of three-phase PWM voltage- and current-source converter topologies in FACTS applications. Proceedings of the IEEE Power Engineering Society Transmission and Distribution Conference, 1(SUMMER), 473-479. https://doi.org/10.1109/pess.2002.1043279

[8] I. Kolosok,E. Korkina \& A. Tikhonov (2020). Application of FACTS devices for flexibility control of transmission networks. E3S Web of Conferences, 209, 02016. https://doi.org/10.1051/e3sconf/202020902016

[9] L. D. Le, D. N. Vo, S. T. Huynh, T. M.Nguyen-Hoang, \& Vasant, P. (2020). A Hybrid Differential Evolution and Harmony Search for Optimal Power Flow With FACTS Devices. International Journal of Operations Research and Information Systems, 11(3), 39-65. https://doi.org/10.4018/IJORIS.2020070103

[10] T. Mahmoud (2019). Power System Stability Improvement Using (Sssc). Journal of Al-Azhar University Engineering Sector, 14(53), 1474-1480. https://doi.org/10.21608/auej.2019.64260

[11] S. A. Mohamed, N. Luo, T. Pujol \& L. Pacheco (2018). Voltage Sourced Converter (VSC) based on multiple FACTS controllers for the improvement of power quality. Renewable Energy and Power Quality Journal, (December),

65-70. https://doi.org/10.24084/repqj16.213

[12] S. L. Nilsson (Ed.). (2020). Flexible AC Transmission Systems. https://doi.org/10.1007/978-3-319-71926-9

[13] R. K. Varma \& J. Paserba (2017). Flexible AC transmission systems (FACTS). In Power System Stability and Control, Third Edition (Second Edi). https://doi.org/10.4324/b12113

[14] F. Wang, Y. Li, \& X. Shi (2016). FACTS, HVDC, and Supergrid. Smart Grid Handbook, 1-18. https://doi.org/10.1002/9781118755471.sgd076

[15] Y. Xue, Y. Zheng, \& S. Rahman (Eds.). (2020). Proceedings of PURPLE MOUNTAIN FORUM 2019International Forum on Smart Grid Protection and Control. https://doi.org/10.1007/978-981-13-9779-0

[16] G. Yue, C. Zhiqiang, S. Jia, W. Xudong, L. Yun, \& M. Shiqian (2018). Power Flow Adjustment Capability Research of SSSC Accessed to Power Grid. 2nd IEEE Conference on Energy Internet and Energy System Integration, EI2 2018 - Proceedings, 1, 1-9. https://doi.org/10.1109/EI2.2018.8582399

[17] X.-P. Zhang, C. Rehtanz \& B. Pal (2012). FACTSDevices and Applications. https://doi.org/10.1007/9783-642-28241-6_1

[18] P. Zuniga-Haro \& J. M. Ramirez (2008). Multipulse VSC based SSSC. 2008 IEEE Power and Energy Society General Meeting - Conversion and Delivery of Electrical Energy in the 21st Century, 1-8. https://doi.org/10.1109/PES.2008.4596517 